\title{
Questôes epistemológicas e bioéticas da prevenção quaternária
}

| ${ }^{1}$ Clara Costa Oliveira, ${ }^{2}$ Ana Reis |

Resumo: Este artigo avalia a atual tendência conceitual

1 Professora associada pela UCP doutora e associada pela UM, em Medicina Geral/Familiar, Saúde Pública e Coletiva, no tocante à prevenção quaternária. Os objetivos são identificar e divulgar esse tipo de prevenção e refletir epistemológica e eticamente sobre seus discursos. A metodologia utilizada é qualitativa, de tipo hermenêutico. Começamos por relembrar as três dimensões da prevenção da doença, desenvolvendo sua quarta forma, que é uma espécie de prevenção das anteriores. Em seguida, abordamos a atribuição da urgência de prevenção quaternária a alguns grupos específicos: médicos, idosos, "pseudo-doentes" e doentes psiquiátricos. Depois, avaliamos se os princípios-base da Bioética são ou não abordados (e o quão desenvolvidos) nesse tipo de prevenção. Ainda que tenhamos delineado algumas críticas anteriormente, abrimos uma seção especialmente para isso, na qual desmontamos epistemológica e eticamente textos dessa linhagem, que resultam em discursos nem sempre coerentes nem coadunados com a prática clínica efetiva. Salientamos o discurso dualista que se esconde por trás da maior parte dos textos, e que anula o pretenso holismo que defendem. O resultado da pesquisa é que os principais defensores desse tipo de prevenção utilizam um discurso nem sempre coerente, quer epistemologica, quer eticamente. Concluímos que, sendo uma expressão muito útil na prática clínica, a prevenção quaternária precisa ser aclarada teoricamente e mais divulgada entre - e dialogada com - profissionais de saúde de várias especialidades.

> Palabras-clave: prevenção quaternária; epistemologia; bioética. de Educação da Universidade do Minho. Endereço eletrônico: claracol@ie.uminho.pt

2 Doutora em Bioética (UCP); professora coordenadora convidada da CESPU-ESSVA, Portugal. Endereço eletrônico: ana.greis@sapo.pt 
Desde os primórdios da civilização humana, o homem experimentou medidas de âmbito comunitário visando à promoção da saúde e à prevenção da doença; é inegável a importância da prevenção para atual concepção de saúde.

Nos países ditos desenvolvidos, a prevenção se direcionou sobretudo para estudos clínicos e epidemiológicos. No âmbito da formação de profissionais de saúde, ainda se verifica que certos conceitos não se distinguem claramente: práticas de promoção da saúde são identificadas por vezes como de prevenção de doenças. No espaço clínico, as atividades também não se diferenciam. É nesse contexto que surgiu a prevenção quaternária, que aqui vamos abordar criticamente.

\section{Níveis de prevenção da doença}

A saúde preventiva focaliza-se quase em exclusivo sobre a tomada de medidas para prevenir as doenças, em vez de curar ou tratar seus sintomas. Até há pouco tempo, considerava-se que existiam três níveis de prevenção em saúde: prevenção primária, secundária e terciária. Não havendo unanimidade sobre esses conceitos (há quem diferencie uma prevenção primordial da primária, por exemplo), iremos abordá-los rapidamente, recorrendo a suas conotaçōes mais frequentes e aceitas.

A divisão da prevenção, bem como sua caracterização, surgiu pela primeira vez, acredita-se, num texto de Leavell e Clark (1976), nos anos 60. A prevenção primária dirige-se geralmente à sociedade em geral, incluindo populaçôes saudáveis (sem patologias fisiobiológicas diagnosticadas). Ela pretende diminuir ou anular o surgimento de patologias em pessoas ou grupos, alertando-os para fatores de risco. O exemplo mais clássico do caso é a vacinação em geral, mas podemos mencionar as campanhas nacionais, por exemplo, a favor do uso de preservativo (HESPANOL; COUTO; MARTINS, 2009).

A prevenção secundária planeja, operacionaliza e dirige atividades para pessoas e grupos saudáveis, ou para doentes. No primeiro caso, pessoas e grupos são considerados mais vulneráveis (por fatores genéticos ou de estilo de vida, por exemplo) face a uma patologia específica (como diabetes de tipo II ou a gripe). No caso de doentes, esse tipo de prevenção aplica-se àqueles em fase preliminar da patologia (pessoas com níveis ligeiramente elevados - face à média estatística normalizante - de colesterol "mau”: LDL, por exemplo). 
Finalmente, o objetivo principal da prevenção terciária é reabilitar os doentes com patologias instaladas, nomeadamente (e crescentemente) os doentes crônicos, como os coronários. Ainda que possa dirigir-se a grupos específicos, é usualmente realizada individualmente.

O conceito de prevenção quaternária é atribuído a Jamoulle, médico de saúde familiar belga, e foi aceito pela WONCA (World Organization of National Colleges, Academies and Academic Associations of General Practitioners/Family Physicians) em 2003 (JAMOULLE; ROLAND, 2011). Ele foi criado para proteger a população em geral das medidas médicas fúteis e de iatrogenias, tanto no nível diagnóstico como no terapêutico. Vários autores a ele se têm referido, na América e na Europa, incluindo portugueses e brasileiros. Devemos lembrar, no entanto, que o conceito decorre de preocupaçōes demonstradas em todo o mundo quanto à sobremedicalização, as quais podemos ver expressas em 1997 na declaração de Jacarta (OMS, 1997).

Embora sua relevância ainda seja discutida, destacam-se situações do cuidado médico gerador de grande iatrogenia: excesso de rastreios, de solicitações de exames complementares e de medicalizações de fatores de risco, o que coloca a prevenção quaternária como "preventora das demais", sobretudo da primária.

A principal crítica aos rastreios dirige-se àqueles efetuados nas prevenções primária e secundária, pelo índice de ansiedade que causam nas populações (enquanto esperam os resultados, por exemplo). Mesmo na prevenção secundária, e até na terciária, esses rastreios devem ter sempre em conta a ponderação dos benefícios com os malefícios possíveis para a pessoa enquanto tal, e não só no que diz respeito a uma determinada patogenia. No nosso entender, a situação mais preocupante talvez seja a dos testes genéticos, já divulgada - e reclamada - por populações com poder econômico, em todo o mundo. Jovens com histórico de determinado tipo de câncer na família veem-se confrontados com testes genéticos indicando uma probabilidade alta de contrair a doença; decidem (usualmente com o patrocínio de profissionais de saúde) extirpar partes do seu corpo, para evitar o aparecimento de um eventual câncer. A prevenção quaternária implicaria, por exemplo, antes da realização dos testes genéticos, explicar aos potenciais doentes: o que é a lei de Mendel (que continua a vigorar como lei genética); o que é uma probabilidade e como ela é estabelecida; o que sabemos (e sobretudo o que não sabemos) sobre o surgimento de cânceres em determinados órgãos; e 
se uma tendência genética pode, ou não, ser transposta para o organismo como um todo (ou para órgãos que desempenham funções do mesmo tipo), em vez de ser direcionada para apenas um órgão. Antes de tudo, convinha talvez que essas pessoas sãs percebessem o que são genes - e que os médicos também não o esquecessem - em vez de substancializarem interações processuais físicoquímicas (JAMOULLE; ROLAND, 2011).

Quanto aos exames complementares, todos nós temos que reconhecer que passaram de auxiliares de diagnóstico a exames imprescindíveis para este, com algumas honrosas exceções. Raramente, aliás, um médico arrisca um diagnóstico sem ter anteriormente avaliado os exames "complementares". Assim, para os defensores da prevenção quaternária, esses exames deverão ser apenas solicitados quando houver dúvida quanto ao diagnóstico. Note-se que raramente há certeza absoluta, até por a medicina não ser uma ciência exata. Admite-se também o requerimento desse tipo de exames quando há suspeita de diagnóstico grave. De algum modo, os autores remetem a maior parte desse tipo de exames para a prevenção terciária, e ainda assim com parcimônia, de modo a não disparar níveis de ansiedade e preocupação nos doentes, os quais causam mais malefícios que possíveis indicações facilitadoras de diagnóstico (NORMAN; TESSER, 2009).

As situações acima descritas relacionam-se a um dos maiores perigos da prevenção da doença, em qualquer dos seus níveis: a patologização dos fatores de risco. A indústria farmacêutica conseguiu convencer a população em geral, e muitos dos profissionais de saúde, que um fator de risco deve ser medicalizado, ou seja, é tornado uma doença algo que é apenas um indicador possível (geralmente, nem sequer provável, a não ser face a índices muito altos) e que deve ser sempre avaliado em relação a uma série de outros fatores, sobretudo uma consulta médica cuidadosa e cuidadora. A existência do grande número de substâncias genéricas (como a sinvastatina) em países como Portugal identifica claramente o poder da indústria farmacêutica na criação de necessidades medicamentosas por puro marketing (ILLICH, 1997).

\section{Prevenção quaternária e públicos específicos}

O público que mais necessita de prevenção quaternária parece, pois, ser o das pessoas saudáveis, sujeitas às prevençóes primária e secundária. 
Outro grupo muito necessitado é a própria classe médica (HESPANHOL; COUTO; MARTINS, 2009), dado seu poder de diagnóstico e prescrição de exames e medicamentos. Os excessos dos médicos nesses domínios são consequência, muitas vezes, da pressão dos próprios doentes e de suas famílias, de seus pares, superiores hierárquicos e, enfim, da representação social de médico que a nossa cultura foi construindo. Se existem atualmente restriçôes quanto à prescrição de exames e medicamentos, tal ocorre por mera questão financeira, de controle de custos. Mas suponhamos que um médico prescreva muito menos do que o limite que lhe foi atribuído. Não será considerado algo estranho? Claro que sim. As restriçôes a que a classe médica está sujeita não significam - na maior parte dos casos - estarmos face a uma situação de prevenção quaternária por parte dos serviços administrativos e dos dirigentes das instituições de saúde.

Esse imaginário social sobre o papel do médico relaciona-se diretamente com a pressão da indústria farmacêutica que já mencionamos, e que é um dos poderes econômico-financeiros mais fortes do mundo (ILLICH, 1997). Seu investimento crescente na patologização dos fatores de risco, por exemplo, leva à pressão por seus pares - com a criação de protocolos e objetivos a alcançar fortemente focalizados na prevenção primária, por exemplo (GERVAS, 2006; MELO; SOUSA, 2011) - e pelos próprios usuários. O risco de ser acusado de negligência médica, seja por seus pares, por seus superiores ou pelos usuários (doentes ou saudáveis), leva muitos médicos a se defender da situação reforçando o papel social que lhes é atribuído, de escrevinhadores de receituário.

Esse nível de prevenção é considerado pertinente no que se refere ao cuidado médico de idosos, especialmente no risco de medicalização acrescida e desnecessária (ALMEIDA, 2005; KUEHLEIN; SGHEDNI; VISENTIN, 2011). Devemos, no entanto, salientar que esse é o grupo etário no qual os médicos se sentem menos vinculados a "investir", em oposição ao das crianças. Isso decorre do mito cultural de que existem idosos a mais e de que a medicina conseguiu controlar a maior parte das doenças. Se tal é verdade quanto às de foro infecto-contagioso, o mesmo não podemos afirmar no que diz respeito às doenças crônicas, elas próprias consideradas durante muito tempo consequência da longevidade acrescida. $\mathrm{O}$ aumento de crianças e jovens com doenças crônicas, porém, tem colocado em causa essa premissa. Além disso, um olhar atento à pirâmide demográfica portuguesa (considerado um dos países mais envelhecidos 
do mundo) constata que o que torna o país cada vez mais idoso não é tanto o número acrescido de sêniores, mas sobretudo a muito baixa natalidade: cerca de 1,3 filho por cada mulher fértil (FERNANDES, 2007). No entanto, não se detecta por parte da classe médica, por exemplo, um alerta para essa questão, que também traz problemas graves para o sistema nacional de saúde.

No que se refere aos idosos, repetimos, eles são considerados um dos grupos que a prevenção quaternária deverá privilegiar, sendo a razão mais comum indicada a sua probabilidade de contração de "doenças compostas" (NORMAN; TESSER, 2009).

Alguns dos mais acres defensores (e até criadores) da prevenção quaternária (KUEHLEIN; SGHEDNI; VISENTIN, 2011) identificam o grupo de doentes fibromiálgicos - ou com diagnóstico de fadiga crônica, em alguns países identificado com o de fibromialgia (DELUCA, 2001) - como uma população especialmente necessitada de prevenção quaternária. Se em alguns desses textos assumem que se trata de patologias que podem levar a uma sobremedicalização, em outros elas aparecem como pseudopatologias (MELO, 2007), dado entenderse que são "meras doenças psíquicas", ou de foro psiquiátrico (doenças mentais). Os autores revelam nesse tipo de ajuizamento, para nós, crenças formativas e paradigmáticas fortemente discriminatórias, quer desses doentes, quer de todos os de foro psiquiátrico, raciocínio que desenvolveremos posteriormente. No momento, não podemos deixar de lembrar que a fibromialgia, bem como a síndrome de fadiga crônica, só pode ser diagnosticada por exclusão de outras patologias, dado não se conhecerem fatores causais simples. Daí terem os doentes que sujeitarse a exames auxiliares complexos, como testes imunológicos e ressonâncias magnéticas. Dado não haver outra possibilidade de diagnóstico validado até ao momento, consideramos diletante (e ofensivo para os doentes) considerar que os exames médicos serão excessivos nesse diagnóstico. Além disso, existem estudos que remetem para forte evidência de disfuncionamento neurofisiológico (DELUCA, 2007) nessa doença, que tem sido cada vez mais considerada de foro neuromuscular (RODERO; CASANUEVA; HOYO, 2010), ainda que sobre tal não haja consenso. Obviamente, uma má compreensão da fibromialgia (para já não falar de um mau diagnóstico) pode levar a uma sobremedicação (inútil, além de nefasta) dessa doença, o que implica uma prevenção quaternária de foco nos 
médicos (bem como de uma atualização científica), e não propriamente nesse grupo de pacientes. Mas voltaremos a essa temática mais adiante.

Outro grupo avaliado como devendo ser alvo prioritário da prevenção quaternária é o dos doentes psiquiátricos. Nos textos a que tivemos acesso, porém, essa afirmação não passa, praticamente, disto mesmo: uma afirmação, sem grande justificação. Apenas é indicado que esse tipo de doentes é privilegiadamente tratado pelos médicos de saúde familiar, face aos psiquiatras, por os primeiros se fundamentarem numa abordagem biopsicossocial e os segundos, supostamente, no paradigma biomédico (biomecânico, no nosso entender) (JAMOULLE; ROLAND, 2010).

Ainda no mesmo texto, o criador da prevenção quaternária brinda-nos com juízos de valor, ora explicitados, ora velados, sobre a superioridade da abordagem do médicos de família face à dos colegas psiquiatras, por os primeiros se focalizarem mais na relação médico-doente, e não tanto na classificação das doenças de tipo psiquiátrico. Paradoxalmente, no entanto (no nosso entender), defende que os instrumentos de classificação da medicina familiar são muito ajustados para diagnóstico desse tipo de patologia.

Jamoulle parte do princípio de que apenas os médicos de saúde familiar abordam os seus doentes de forma eficaz, no que se refere à comunicação, e que apenas eles privilegiam uma abordagem biopsicosocial. Trata-se de uma premissa paternalista, e que revela demasiada confiança em todos os médicos que partilham de sua especialidade. Contudo, ainda que aceitemos essa premissa, dela não se pode inferir com validade lógica que uma abordagem biopsicossocial e de grande confiança na relação médico-doente previna este último de abuso de medicalização ou de excesso de exames diagnósticos, por exemplo. A pressão sobre o médico pode até aumentar, quer pelo relacionamento mais próximo, quer devido a uma abordagem mais global do usuário, que não se restringe à busca de algo que ocorre num órgão específico, mas antes a eventuais interações sistêmicas desse órgão em todo o organismo, nomeadamente no nível da disfuncionalidade.

Para alguns autores, a prevenção quaternária equivale à "prevenção do sofrimento". Vinculam-na, nesse sentido, aos cuidados paliativos, pretendendo promover a construção de sentido do sofrimento dos próprios doentes, bem como de seus familiares (OMS, 2002). 
Ainda que mencionem os autores vinculados aos cuidados de doentes oncológicos, os defensores da prevenção quaternária não colocam em causa essa conotação (HESPANHOL; COUTO; MARTINS, 2008), o que se nos afigura como surpreendente, dado a sua defesa de uma medicina holista. Ora, nessa visão, a finalidade da medicina não é mero tratamento do corpo doente (LEBRETON, 1995), mas sim o alívio do sofrimento humano. Assim sendo, não podemos circunscrevê-lo aos cuidados paliativos, por mais importantes que os consideremos. A significação atribuída a uma quarta fase do alívio do "sofrimento", associando-a explicitamente aos cuidados paliativos oncológicos, surge nos textos como sinônimo daquilo a que, no nosso entender, seria mais correto chamar "alívio da dor", ou da dor total. Segundo Cassel, o sofrimento é um estado de aflição severa associada a eventos que ameaçam a integridade (intactness) de uma pessoa (2005, p. 32).

\section{Princípios bioéticos e prevenção quaternária}

Nos documentos produzidos pelos defensores da prevenção quaternária reivindicam-se explicitamente os princípios bioéticos da não maleficiência (primum non nocere), da proporcionalidade (GERVAS, 2006) da justiça (como equidade) e da autonomia (NORMAN; TESSER, 2009). Assim, o conceito de prevenção quaternária tenta recuperar o preceito hipocrático da não maleficiência, que durante mais de um milênio (juntamente com o princípio da beneficência), regrou eticamente a conduta médica. No decorrer do século $\mathrm{XX}$ (sobretudo, ao longo da segunda metade), os princípios de autonomia e de justiça foram, porém, ganhando terreno, sendo, pois, curioso que uma das áreas da Medicina que mais tem pugnado pelo princípio da justiça venha agora reclamar a recuperação do princípio de não prejuízo do doente, em caso de dúvida (JAMOULLE; ROLAND, 2005).

$\mathrm{O}$ conceito tem congregado cada vez mais médicos de família, que o reclamam como útil no âmbito da Saúde Familiar/Coletiva e dos sistemas nacionais de saúde, mormente em épocas de contenção de gastos, pois remete para uma utilização de recursos mais cuidadosa. Para muitos, isso poderá levar a uma maior equidade nos serviços de saúde, pois aquilo que se vai poupar com o que é desnecessário poderá ser utilizado para quem tem efetiva necessidade. É nesse sentido que os defensores da prevenção quaternária parecem entender o 
princípio de justiça, dado não termos encontrado uma defesa ou fundamentação

mais desenvolvida. Valoriza-se, pois, a concentração de meios tecnológicos e medicamentosos para a prevenção terciária, em detrimento (mas não exclusão) da primária e da secundária (HESPANHOL; COUTO; MARTINS, 2008).

O princípio de autonomia encontra-se, nesses autores, fortemente conectado comode proporcionalidade, queadvém do Direito. Nessaárea, a proporcionalidade, latu sensu, refere-se às relações jurídicas do Estado com os membros de uma sociedade, remetendo à salvaguarda dos direitos dos cidadãos face à capacidade punitiva do Estado, que deve tender para uma proporcionalidade, ou seja, não deve ser muito desigual.

No âmbito da prevenção quaternária, a proporcionalidade deve ser enquadrada na relação médico-doente, onde aquele não deve exercer sobre este um papel coercivo, dominador e sapiencial, mas antes deve tentar estabelecer um clima de relacionamento baseado na confiança mútua, que permita ao doente exercer a sua autonomia. Ora, como sabemos, em Bioética, não existe autonomia sem consentimento informado e - ainda que os autores deste vertente preventiva nem sempre o mencionem - ele encontra-se implícito nos seus escritos (ALMEIDA, 2005).

Sendo o domínio da prevenção da doença reclamado pelos médicos de saúde familiar, tão divulgada e acalentada pela ONU, encontramos, sem surpresas, os seus juízos e valores quanto a esse assunto vinculados a documentos da mesma instituição, relativos à Bioética (UNESCO, 2006).

\section{Críticas à prevenção quaternária}

Algo em que eventualmente o leitor deste artigo já pensou foi o fato de a prevenção quaternária mais não ser que um posicionamento já clássico no âmbito da Bioética, nomeadamente na de cariz médico, contra os atos de futilidade terapêutica. Seus defensores parecem, no entanto, desprezar esse posicionamento, bem como a crítica da distanásia, sobretudo em cuidados paliativos (oncológicos ou outros), que mais não faz que retomar o princípio do primum non nocere. Talvez isso ocorra por os médicos de família não se depararem com tantas situações de distanásia como colegas seus de outras especialidades.

Ainda no âmbito da Bioética, ficamos com dúvidas sobre o uso da autonomia por parte do doente. Se os textos da prevenção quaternária são claros quanto à 
recusa do doente em recorrer a determinados tratamentos/exames a conselho de seu médico, quanto ao uso da opção positiva por esses mesmos doentes, os textos não são tão claros. Caso o médico considere desnecessários ou inúteis determinados exames/tratamentos, e o doente decida autonomamente realizá-los, os médicos da prevenção quaternária aceitarão a decisão dos doentes, ou usarão sua autoridade desproporcional, recorrendo ao argumento de que os usuários não se encontram suficientemente esclarecidos, podendo também justificar a decisão contrária à dos doentes em nome do princípio da justiça, da distribuição de recursos de modo mais equitativo? Nossas dúvidas decorrem de os textos acentuarem o princípio da autonomia pela negativa: "[A prevenção quaternária] implica, além disso, um compromisso ético e profissional, a ética da negativa, que consiste, sucintamente, em recusar intervenção quando desnecessário" (NORMAN; TESSER, 2009, p.2015).

Continuando no campo da Bioética, surpreende-nos a não utilização do princípio de responsabilidade quanto à tecnologia, de Jonas (2006), para alicerçar a prevenção quaternária; talvez o autor possua em seu pensamento premissas (como a revalorização da teleologia) que se opõem às crenças da prevenção quaternária, como veremos.

$\mathrm{O}$ aspecto que para nós merece mais críticas prende-se à quase total inexistência de uma teoria fundamentadora da prevenção quaternária; existe alguma ideologia pela negativa, mas não se encontra um quadro conceitual estruturado e coerente. Tal situação não é, aliás, nova no quadro da promoção da saúde, estando mesmo, para nós - e para vários autores (TONES; TILFORD, 2001) -, na razão de ser de ela se ter transformado, na maior parte dos casos, em mera prevenção da doença.

$\mathrm{Na}$ ausência de tal quadro teórico, os textos promotores da prevenção quaternária ora se situam pela negativa, face a procedimentos/açôes terapêuticas, ora utilizam um vocabulário muitas vezes em consonância mais com os alicerces epistemológicos daquilo que atacam do que daquilo que pensam defender.

Ainda que não possamos explorar detalhadamente esse assunto, deixamos o leitor com algumas questôes que desmistificam, no nosso entender, o vanguardismo reivindicado pela prevenção quaternária.

Os textos da prevenção quaternária por nós consultados, incluindo os de seu fundador, revelam a crença num dualismo que impossibilita a visão holista pela qual querem ser reconhecidos. O dualismo epistemológico sujeito/objeto, 
de origem grega, foi-se ajustando à evolução da cultura humana ocidental, onde se inclui a ciência mecanicista, cujos fundamentos definitivos se devem a Newton. Assim, uma das formas mais antigas desse dualismo é o da oposição corpo/espírito, que no século XX tomou a roupagem de corpo/mente (também existe o dualismo mente/espírito). Todos eles se articulam entre si, estando profundamente arraigados na nossa civilização; somente uma reflexão séria sobre os fundamentos das nossas crenças científicas, nesse caso, possibilita-nos deles termos consciência e deles efetivamente afastarmo-nos, se assim entendermos.

Quando vários dos autores aqui referenciados consideram que a prevenção quaternária evitará medicação de falsos doentes, por apenas sofrerem de enfermidades de foro psiquiátrico, ou psíquico, estamos lidando diretamente com duas crenças: (1) o corpo é distinto da mente/psique; e (2) a doença só diz respeito ao corpo. "Na prevenção quaternária, temos o problema da enfermidade sem doença” (KUEHLEIN; SGHEDNI; VISENTIN, 2011, p. 8). Assim, temos que enfermidades com dimensão mental/psíquica/psicológica não são doenças por não possuírem uma causa somática. Temos então que depreender que a mente e a psique radicam numa res cogitans cartesiana, mas ainda mais distante que ela do corpo, dado nem sequer com ele comunicar por uma eventual glândula pineal cartesiana. Existem mentes humanas sem corpo?

Esse tipo de raciocínio devia lembrar-nos que um corpo pode manterse vivo sem qualquer atividade abstrata (mas sempre com alguma atividade cerebral básica, nem que seja do sistema límbico), enquanto não é possível manter cérebros a funcionar sem atividade corporal, da qual a mente faz parte. Fazemos notar, aliás, que estamos longe de termos obtido consenso cultural sobre o que é uma mente humana (na filosofia esta questão é estudada há cerca de 6000 anos, pelo menos), mas seja o que for (e será certamente algo de nível processual, e não substancializado), envolve inevitavelmente o cérebro, que pertence ao corpo humano, tal como o fígado ou o coração. Além disso, do cérebro e para o cérebro convergem os sistemas nervosos central e periférico, que percorrem todo o corpo humano. Como podemos então considerar que uma dor "psicossomática" não deve ser tratada como uma outra dor, digamos nociceptiva? Não precisa esta do sistema nervoso para existir? Então quando temos dores nas quais o próprio sistema nervoso está afetado (ainda que não se saiba como), como nas neuropatias, podemos afirmar que não são dores somáticas? A maior 
parte dos clínicos especialistas em dor humana tem evitado empregar o chavão "dor psicossomática", devido ao avanço que se tem verificado no estudo e funcionamento de dores de tipo neuropático:

In the 1930s it was revolutionary to suggest that something in the mind could lead to somatic diseases. Today, I submit (though many would disagree), we are held back by the concept, because it implies that some diseases are psychosomatic and others are not. It perpetuates dualistic thinking and prevents us from seeing that all human distress is always that of an integrated organism, always has a psychic (and a social, I might add) and a somatic aspect (ANTONOVSKY, 1996, p.11).

Doenças mencionadas usualmente por estes autores como se tratando de pseudodiagnósticos - "Excessos de diagnósticos (ao rotular sintomas medicamente inexplicados criam-se pseudo-diagnósticos como por exemplo colite, neurose, sindrome de fadiga crónica, fibromialgia, proctalgia fugax, entre outros) “ (MELO, 2007, p. 289) - como a fibromialgia, tem, segundo os médicos de especialidade, como mencionamos anteriormente, um peso somático tão "digno" como qualquer outra patologia. A fibromialgia tem sido tratada, com algum sucesso (prevenção terciária), com substâncias químicas coadjuvantes do alívio da dor em patologias oncológicas (estabilizadoras do sistema nervoso central). Será que podemos considerar que as dores decorrentes do avanço de câncer são também de tipo "psicossomático"?

Ainda no contexto da citação de Antonovsky, afirma-se que os doentes psiquiátricos se sentem aliviados da sua culpa quando obtêm um "pseudodiagnóstico" de uma doença "real", sendo que, para tal, pressionam o clínico familiar/comunitário/coletivo. Notemos que os autores não atribuem esse tipo de afirmação a uma mitificação da doença psiquiátrica; antes, pelo contrário, a legitimam e a reforçam. Em nome de que crenças defendem esses autores (e muitos deles acadêmicos, com responsabilidades na investigação científica) que o diagnóstico de "enfermidade" psiquiátrica acarreta culpa? Para justificar esse tipo de afirmações, talvez tivéssemos de nos reportar à crença de que a doença é um castigo divino, sendo que esses médicos vinculariam esse fardo apenas às "enfermidades" psiquiátricas.

Este tipo de raciocínio conta também com dois elementos que não podemos deixar de assinalar, ainda que não os possamos desenvolver pormenorizadamente: a crença na atuação exclusiva de causalidade de tipo eficiente (eventualmente formal) no surgimento da doença, e a crença na saúde como ausência de doença, 
ainda que o neguem. Mas não basta negá-lo, há que praticá-lo, nomeadamente naquilo que se escreve.

A defesa de uma abordagem holista da pessoa implica perspectivá-la como alguém que é muito mais do que a soma de suas partes, e onde diversas variáveis e, sobretudo, processos metabólicos podem causar desequilíbrio orgânico (onde estão incluídas as dimensões emotiva, fisiológica, comunitária, ética, volitiva, espiritual, molecular, etc.). Todas essas divisões são apenas do âmbito observacional, e delas precisamos para produzir ciência; mas não confundamos o mapa com o território, nem atribuamos (toda, pelo menos) a culpa à vítima. O sofrimento de um hipocondríaco é tão real como o sofrimento de um doente com uma úlcera diabética; essa realidade não pode ser esquecida, ou estaremos a utilizar a prevenção quaternária para encapotar negligência médica. A finalidade da medicina é sempre minorar o sofrimento de doentes, e seus familiares, e não apenas em situações de cuidados paliativos. As pessoas que sofrem sem diagnóstico preciso devem ser cuidadas à luz do princípio da vulnerabilidade, e não serem sujeitas a juízos discriminatórios.

Outro assunto que não podemos deixar de referir é a convicção de que a prevenção quaternária se deve alicerçar na Medicina baseada na evidência (EBM). Convinha que os autores delineassem com clareza como articulam o tipo de causalidade, o número de vaiáveis, o juízo pouco complexificante que se utiliza na EBM com as perspetivas holistas e centradas na pessoa (individual, supõe-se, e não estatística).

Muitos médicos consideram-se muito pouco satisfeitos com a sua prática clínica, exatamente por se sentirem pressionados pelos imensos estudos delineados na prevenção da doença, baseados em EBM (OFRI, 2010; FUCHS, 2011). Assim, a EBM não fundamenta em exclusivo a prevenção quaternária, mas também muito daquilo que ela combate.

Frequentemente, estes dois princípios da ética médica, a beneficência e a não maleficência, apontam para decisões opostas e este equilíbrio pode dificultar a decisão na prática clínica. A epidemiologia e a medicina baseada na evidência têm, de certa forma, contribuído para tentar auxiliar, nesta perspetiva, os médicos e os pacientes nas decisões a tomar. Vão nesse sentido a criação e utilização cada vez mais comum dos conceitos «número necessário para rastrear/tratar» (NNR/T) e «número necessário para danificar» (NND). O NNR/T indica-nos o número de pacientes que é necessário rastrear ou tratar, durante o período de tempo que durou o ensaio, para evitar um evento adicional e, na prática, traduz uma forma de medir o grau de beneficência de uma determinada intervenção (HESPANHOL; COUTO; MARTINS, 2008, p.52). 
Por fim, um reparo mais suave: seria interessante vermos indicadas pelos defensores da educação quaternária medidas promotoras de saúde, e não apenas preventivas de patologias acrescidas por prevenção excessiva. Atividades organizadas comunitariamente, ligadas ao lúdico, ao lazer, à alegria, à partilha, e à criação e gestão de recursos gerais de resistência, bem como à construção de sentido interno de coerência (ANTONOVSKY, 1996), talvez fossem uma eficaz força de prevenção quaternária.

\section{Promoção da prevenção quaternária}

Apesar das críticas que aqui expressámos, consideramos a prevenção quaternária uma expressão útil para o mundo da promoção da saúde. Poderia sê-lo muito mais se as questões anteriormente mencionadas (e outras) fossem levadas em conta. $\mathrm{O}$ primeiro passo para uma efetivação daquilo que esses autores nos preconizam é, sem dúvida, a divulgação do conceito.

A divulgação e aceitação da prevenção quaternária, porém, exigem um quadro teórico sólido, coerente, não isolado para médicos de saúde familiar. Muitos doentes (como os idosos e doentes de várias patologias crónicas) são seguidos por médicos de várias especialidades, pelo que o perigo da medicalização nociva é acrescido. Assim, a prevenção quaternária não pode continuar a ser divulgada quase em exclusivo no mundo dos médicos generalistas (KUEHLEIN; SGHEDNI; VISENTIN, 2011). Ela será muito mais fácil de se impor se os vários profissionais de saúde (e não só os médicos) trabalharem articuladamente em equipe. Enfermeiros, assistentes sociais, farmacêuticos e psicólogos, entre outros, possuem um papel preponderante no que diz respeito aos cuidados de saúde primários, pelo que não podem deixar de ser ouvidos e envolvidos nos indicadores definidos pelos serviços da instituição de saúde (MELO; SOUSA, 2008). Veja-se o caso dos serviços domiciliários, que envolvem uma promoção da saúde de articulação desses técnicos com o próprio doente e seus familiares.

Um dos outros caminhos apontados é o da capacitação (empowerment) das populaçôes; no entanto, de novo, ela se indica como sendo tarefa dos médicos generalistas ${ }^{5}$, por parte de alguns dos defensores desse tipo de prevenção. Outros, porém, não parecem restringi-la a qualquer especialidade (ALMEIDA, 2005).

Falta ainda, todavia, outro passo fundamental para a capacitação das pessoas em geral: a colaboração da promoção formal da saúde (levada a cabo sobretudo 
por profissionais da área) com os profissionais das ciências sociais que atuam

formal e informalmente, em ONGs, autarquias e outras formas de poder local, instituições religiosas, escolas, etc. Esses técnicos possuem um contato próximo e privilegiado com as populações, e uma efetiva prevenção quaternária que promova a saúde não trará resultados se não se aliar a esses profissionais. Muitos deles possuem um papel preponderante nas prevenções primária e secundária, principais focos de crítica da prevenção quaternária.

Outro aspecto mencionado pelos autores, e com o qual concordamos completamente, é o da relação médico-doente, onde radica a possibilidade de uma efetiva prevenção quaternária, em contexto médico. Saber escutar, olhar nos olhos, saber calar, são atributos muito valorizados, entre outros, pelos usuários. Estes contam com o saber do médico, mas também com a possibilidade de serem tratados como seus iguais, do ponto de vista humano.

Nesse sentido, defendemos que a formação acadêmica de médicos esteja cada vez mais atenta à dimensão comunicacional e à cultura onde os médicos estão inseridos (OMS, 1986). Propomos, pois, uma aposta das Humanidades em Medicina, na formação acadêmica e profissional de médicos, proporcional à formação bioquímica. Para os médicos em exercício, há que se assegurar formação contínua nessas áreas.

Uma última palavra para a necessidade de partilha de instrumentos classificadores de patologias, entre os médicos de várias especialidades (psiquiatras, e outros profissionais de saúde, como psicólogos, por exemplo), nomeadamente no que se refere aos vários classificadores de medicina geral e familiar (MELO; SOUSA, 2011). O ideal seria a constituição de um único instrumento classificador, a ser atualizado continuamente. Isso implicará, repetimos - contudo - que os documentos da medicina geral e familiar (JAMOULLE; ROLAND, 2005) não sejam considerados superiores aos outros. Se assim for feito, a possibilidade de diálogo certamente que será menor (JAMOULLE, 2011).

Esta podia ser uma função despoletada pela OMS, já que ela identifica como estratégia para uma boa prescrição, por exemplo, a distinção entre personal drug (P-drug) e personal treatment (P-treatment) como forma de prevenção do abuso farmacológico (BROEIRO, MAIO, RAMOS, 2008). Ainda nesta linha de pensamento, parece-nos também que seria especialmente útil o estudo da importância da EBM à luz do conceito CLINECS: 
“(...) acrônimo que resulta da fusão das disciplinas que contribuem para a avaliação de serviços de saúde úteis (i.e., valorizados pelo doente ou outros elementos da sociedade): prática clínica, epidemiologia clínica (validade, eficácia e efetividade da intervenção), economia da saúde (eficiência, pagamentos e reembolsos), psicologia, ética e filosofia (valor e justiça) (ALMEIDA, 2010, p. 85)". ${ }^{1}$

\section{Referências}

ALMEIDA, L. Os serviços de saúde pública e o sistema de saúde. Rev. Port. Sau Pub. Lisboa, n. 28, v. 1, p. 79-92, 2010.

. Da prevenção primordial à prevenção quaternária. Rev Port Saúde Pública. Lisboa, v. 23, n.1, p. 91-96, 2005.

ANTONOVSKY, A. The salutogenic model as a theory to guide health promotion. Health Promot. Int. Oxford, v. 11, n. 1, p. 11-18, 1996.

BROEIRO, P.; MAIO, I.; RAMOS V. Polifarmacoterapia: estratégias de racionalização. Rev Port Clin Geral. Lisboa, v. 24, p. 625-31, 2008.

CASSELL, E. The nature of suffering and the goals of medicine. Oxford: Oxford University Press, 2004.

DELUCA, J. (Ed.). Chronic fatigue syndrome (special issue) Applied neuropsychology. Houston, v. 8, n.1, 2001.

FERNANDES, J. A demografia do envelhecimento em Portugal. Algumas reflexóes práticas. In: BRITO, J. (Coord.). O fim da vida. Braga: ALATHEIA, 2007. p. 27-35.

FUCHS, V. The doctor's dilemma: what is "appropriate" care?.N Engl J Med. Boston, v. 365, p. 585-587, 2011.

GERVAS, J., Inovación tecnológica en medicina: una visión crítica. Rev Port Clin Geral. Lisboa, v. 22, p. 723-7, 2006

HESPANHOL A.; COUTO L.; MARTINS C. A medicina preventiva. Rev Port Clin Geral. Lisboa, v. 24, p. 49-64, 2008.

HESPANHOL, A. et al. Educação para a saúde e prevenção na consulta de medicina geral e familiar. Rev Port Clin Geral, Lisboa. v. 25, p. 236-41, 2009.

ILLICH, I. Limites para a Medicina. Lisboa: Sá da Costa, 1997.

JAMOULLE, M. Quaternary prevention. Prevention as you never heard before. Disponível em: http://www.ulb.ac. be/esp / mfsp/quat-en.html. Acesso em: 20 nov. 2011.

JAMOUlLE, M.; ROLAND, M. Champs d'action, gestion de l'information et formes de prévention clinique en médecine générale et de famille. Santé conjuguée. Bruxelles, v. 33, p. 71-77, 2005.

. Mental health inside the primary care; a different mental health? Disponível em: http://docpatient. net/nimh.htm. Acesso em: 16 fev. 2010. 
. Quaternary prevention. Prevention as you never heard before. Disponível em: http://www. ulb.ac.be/esp/mfsp/quat-en.html1995. Acesso em: 18 nov. 2011.

JONAS, H. O princípio responsabilidade. Ensaio de uma ética para a civilização Tecnológica. Rio de Janeiro: Contraponto, 2006.

KUEHLEIN, T. et al. Prevenção quaternária, uma tarefa do clínico geral. Disponível em: http://www.Primary-care.ch/pdf_d/2010/2010-18/2010-18-368_ELPS_port.pdf. Acesso em: 16 nov. 2011.

LEAVELL, S.; CLARK, E. Medicina Preventiva. São Paulo: McGraw-Hill, 1976.

LEBRETON, D. Compreender a dor. Lisboa: Estrela Polar, 1995.

MACDONALD, N. Palliative care: the fourth phase of cancer prevention. Cancer Detection and Prevention. Worcester MA, v. 15, p. 3253-255, 1991.

MELO M.; SOUSA J. Os Indicadores de Desempenho Contratualizados com as USF: Um ponto da situação no atual momento da Reforma. Rev Port Clin Geral. Lisboa, v .27, p. 28-34, 2011.

MELO, M. A prevenção quaternária contra os excessos da Medicina. Rev Port Clin Geral. Lisboa, v. 23, p. 289-93, 2007.

NORMAN, A.; TESSER, C. D. Prevenção quaternária na atenção primária à saúde: uma necessidade do Sistema Único de Saúde. Cad. Saúde Pública. Rio de Janeiro, v. 25, n. 9, p. 2012-2020, 2009.

OFRI, D. Neuron overload and the juggling physician. Lancet. London, v. 376, n. 9755, p. 1820-1821, 2010.

ORGANIZAÇÃO MUNDIAL DA SAÚDE. Carta de Ottawa para a promoção da saúde. Primeira conferência internacional sobre promoção da saúde. Genève: OMS, 1986.

. Declaração de Jacarta sobre promoção da saúde no século XXI. Genève: OMS, 1997.

. National cancer control programmes: policies and managerial guidelines. Genève:

OMS, 2002.

RODERO, B. et al. Validation of the Spanish version of the Chronic Pain Acceptance Questionnaire (CPAQ) for the assessment of acceptance in fibromyalgia. Health Qual Life Outcomes. London, v. 8, p. 8:37, 2010.

TONES, K.; TILFORD, S. Health promotion: effectiveness, efficiency and equity. United Kingdom: Nelson Thornes, 2001.

UNESCO. Declaração universal sobre bioética e direitos humanos. Paris: UNESCO, 2006.

WEINSTEIN, S. Integrating palliative care in oncology. Cancer control. Tampa, v. 8, n. 1, p. 32-35, 2001.

\section{Nota}

${ }^{1}$ As autoras contribuíram igualmente, redigindo na íntegra o presente texto. 


\section{Epistemological and bioethical issues of quaternary prevention}

This paper assesses the current conceptual trend in General Medicine / Family, Public and Collective Health regarding quaternary prevention. The goals are to identify and disseminate this type of prevention and reflect on their epistemological and ethical discourses. The methodology is qualitative, of hermeneutic type. We begin by recalling the three dimensions of disease prevention, developing its fourth type, which is a kind of prevention of the above. Then we address the allocation of the urgency of quaternary prevention to some specific groups: doctors, elderly, "pseudo-patients" and psychiatric patients. Next, we assessed whether the basic principles of bioethics are not addressed (and how developed) in this type of prevention. Although we have previously outlined some criticism, we opened a section especially for this, in which we epistemologically and ethically disassembled texts of that lineage, resulting in speeches not always consistent or aligned with effective clinical practice. We emphasize the dualistic discourse that hides behind most texts, and defeats the defending alleged holism. The research result is that the main proponents of this type of prevention using a speech is not always consistent, either epistemologically or ethically. We conclude that, being a very useful expression in clinical practice, the quaternary prevention needs to be theoretically clarified and more widespread among - and dialogued with - health professionals of various specialties.

> Key words: quaternary prevention; epistemology; bioethics. 